\title{
Predicted Breeding Values for Nine Plant and Fruit Characteristics of 28 Peach Genotypes
}

\author{
Valdomiro A.B. de Souza ${ }^{1}$ and David H. Byrne \\ Department of Horticultural Sciences, Texas A\&M University, College Station, TX 77783-2133 \\ Jeremy F. Taylor \\ Department of Animal Science, Texas A\&M University, College Station, TX 77843
}

Additional Index words. Prunus persica, genotypic values, quantitative inheritance, multiple trait selection, fruit breeding

\begin{abstract}
Breeding values (BVs) for four plant (bloom date, fruit development period, fruit density, and blind node propensity) and five fruit (weight, blush, shape, soluble solids, and titratable acidity) traits of 28 peach [Prunus persica (L.) Batsch (Peach Group)] genotypes used as parents in the Texas A\&M University peach breeding program were predicted using best linear unbiased prediction (BLUP). Data from seedlings of 108 families developed from 42 peach parents were analyzed by using a mixed linear model, with years treated as fixed and additive genotypes as random factors. The precision of the predictions was high for most parental genotypes, as indicated by the correlations ( $\left.\mathbf{r}_{\mathrm{TI}}\right)$ between predicted and true BVs and the standard error of the predictions (SEP). In most cases, the higher the number of progeny, the better the agreement between predicted and true BVs for that parent. Parents with observations from more than 30 seedlings had a $\mathbf{r}_{\mathrm{TI}} \geq 0.90$ and smaller SEPs. For all traits analyzed, the lowest precision (low $\mathbf{r}_{\mathrm{TI}}$ and high SEP) was observed for 'Flordaking', whose predicted BVs was based only on pedigree information.
\end{abstract}

The simplest method of selecting superior individuals as parents in a breeding program is to choose them based on their own performance. For highly heritable traits, this procedure is more efficient than any other procedure (Falconer, 1989; Hansche, 1983). Nevertheless, the efficiency of phenotypic selection in discriminating among superior individuals decreases as the heritability decreases, and becomes very inefficient for traits with low heritability values (Falconer, 1989; Hansche, 1983; Hesse, 1975). Other procedures of parent selection such as those based on progeny testing (Cotterill and James, 1984; Pepper and Namkoong, 1978; Wilcox and DeLorenzo, 1983), combining ability estimations (Cox and Frey, 1984; Gordon 1980), and direct prediction of breeding values (Henderson, 1977, 1983; White and Hodge, 1988) are more reliable than selection based on phenotype only, and are especially suitable for ranking superior individuals for traits with low heritability (Falconer, 1989).

At first, progeny testing appears to be the ideal method of parent selection and the easiest to evaluate potential parents because the mean additive genetic value of an individual is directly sampled in the individual's offspring. In practice, however, it has the serious disadvantage of increasing the generation interval, because the parents cannot be selected until the offspring have been measured (Falconer, 1989). In fruit tree and nut crops, which normally are long generation crops and require large areas for plant evaluation, this is a major disadvantage of progeny testing (Hansche, 1983).

Parent selection based on their predicted breeding values has been applied commonly in animal breeding using the best linear unbiased prediction or BLUP (Henderson, 1977, 1983). In contrast to the other procedures, BLUP makes use of all information on individuals for which records of phenotypic values and pedigree are available. Regardless of distribution of the data points collected, BLUP maximizes the correlation between predicted

Received for publication 23 Feb. 1999. Accepted for publication 27 Mar. 2000. This paper represents a portion of a $\mathrm{PhD}$ dissertation in plant breeding submitted by the senior author. The cost of publishing this paper was defrayed in part by the payment of page charges. Under postal regulations, this paper therefore must be hereby marked advertisement solely to indicate this fact.

${ }^{1}$ Current address: EMBRAPA/CPAMN, Cx. Postal 1, Teresina, PL, Brazil. and true breeding values, and when the model has been correctly parameterized, it maximizes the probability of correctly ranking any two individuals (Taylor, personal communication). However, to our knowledge this procedure has not been used widely outside of animal and forest tree breeding, and to date only one report on its application in fruit crops was found in the literature. BLUP was used to estimate the general combining ability (GCA) and the specific combining ability (SCA) effects for date of ripening in apples [Malus sylvestris (L.) Mill. var. domestica Borkh. Mansf.] (Tancred and Zeppa, 1995).

BLUP assumes that genetic values are unobservable random effects and that genetic variances and covariances are known. Since for the latter assumption this is never the case, this technique is in practice only an approximation of BLUP (Kennedy, 1981). However, under normality, replacing the unknown variances by their restricted maximum likelihood (REML) estimates results in a very close approximation of BLUP (Gianola et al., 1986).

White and Hodge (1989), White et al. (1986), and Huber (1994) have addressed the application of BLUP to forest tree improvement programs. Since fruit and forest trees share several common breeding difficulties (long generation time and large plant size), prediction of breeding values could be a suitable option for fruit tree crops, where selection is based mainly on individual performance. To illustrate the use of BLUP, the breeding values of 28 peach genotypes used as parents in a previously reported genetic study (Souza et al., 1998a, 1998b) were calculated for 9 traits and are discussed in this paper.

\section{Materials and Methods}

One hundred and eight families from crosses among 42 parents (1178 seedlings) were evaluated in 1993, 1994, and 1995. Although 13 fruit traits and 6 plant traits were evaluated (Souza et al., 1998a, 1998b), data for only 9 traits (fruit density, blind node propensity, date of full bloom, fruit development period, fruit weight, percent soluble solids concentration (SSC), fruit titratable acidity, fruit blush, and fruit shape) are presented in this paper. The resulting nine traits measure all of the characters 
studied initially in the previous genetic studies and represent important commercial traits for peach improvement. Of these traits, three had moderate to high heritabilities $\left(h^{2}>0.65\right.$; date of full bloom, fruit development period, and fruit blush) whereas six had low heritabilities $\left(\mathrm{h}^{2}<0.45\right)$. The heritability estimated for all the traits was in the narrow sense (Henderson, 1977, 1983). The seedlings were 3 and 4 years old when evaluated except for those evaluated for blind node propensity of which $45 \%$ were evaluated at 4 and 5 years of age (Souza et al., 1998a, 1998b). Of the 42 parents analyzed in the initial study, only 28 are discussed herein to simplify the presentation. A detailed description of the plant materials used in this study and a complete description of the evaluation procedures are in Souza et al. (1998a, 1998b).

Statistical analysis. With the exception of fruit titratable acidity and fruit blush, the data were transformed (Box and Cox, 1964) to improve normality. The predicted breeding values were transformed back to the original scale (Souza et al., 1998a).

The analyses were performed using the following mixed linear model:

$\mathbf{y}=X \beta+Z \mathbf{u}+Z \mathbf{v}+\mathbf{e}$, where $\mathbf{y}$ is the vector of observations of length $\mathrm{N} ; \beta$ is a vector of length $\mathrm{p}$ containing fixed effects; $\mathbf{u}$ is a vector of length $g$ containing random effects (breeding values); $\mathbf{v}$ is a vector of length $g$ containing uncorrelated random permanent environment and nonadditive genetic effects; $X$ is the known $\mathrm{N}$ $\times \mathrm{p}$ matrix relating observations in $\mathrm{Y}$ to elements in $\beta ; \mathrm{Z}$ is the known $\mathrm{N} \times \mathrm{g}$ matrix relating observations in $\mathrm{Y}$ to elements in $\mathbf{u}$; $\mathbf{e}$ is the random vector of residuals of length $\mathrm{N}$; and

$\mathrm{E}\left[\begin{array}{l}\mathrm{u} \\ \mathrm{v}\end{array}\right]=\left[\begin{array}{l}0 \\ 0\end{array}\right]$ and $\operatorname{Var}\left[\begin{array}{l}\mathrm{u} \\ \mathrm{v}\end{array}\right]=\left[\begin{array}{cc}A \sigma^{2} & 0 \\ 0 & I \sigma^{2}{ }_{\mathrm{v}}\end{array}\right]$

The predicted breeding values were obtained by using best linear unbiased prediction (BLUP) (Henderson, 1977, 1983). The procedures were as described by Boldman et al. (1995) and Souza et al. (1998a).

\section{Results and Discussion}

Correlations between the predicted and true $\mathrm{BVS}\left(\mathrm{r}_{\mathrm{TI}}\right)$ and the standard error of the predictions (SEP) over all the traits considered herein indicate precise predictions of BVs for most parents (Table 1). The greatest precision was for the parents with the highest number of seedlings. Those with more than 30 seedlings had a mean $\mathrm{r}_{\mathrm{TI}}$ of at least 0.90 and lower SEPs. 'Flordaking' had the lowest precision, since its breeding values were estimated only from pedigree information.

The best parents for individual traits are easily selected (Table 2) from their individual BVs for the traits. Thus, for early bloom 'Tropic Beauty' is best, for low fruit development period (FDP) 'Goldcrest' and 'Springold' are best, for high fruit weight TX35882 is best, for high SSC 'Dixiland' and 'Redskin' are best, and so on. Unfortunately the breeder's job is to combine the best values

Table 1. Chilling requirement, ${ }^{\mathrm{z}}$ number of crosses and seedlings evaluated, and range and mean of $\mathrm{r}_{\mathrm{TI}}$ for each parent.

\begin{tabular}{|c|c|c|c|c|c|}
\hline Parent & $\begin{array}{c}\text { Chilling } \\
\text { requirement }^{\mathrm{z}}\end{array}$ & $\begin{array}{c}\text { No. of } \\
\text { crosses/ } \\
\text { parent }\end{array}$ & $\begin{array}{c}\text { No. of } \\
\text { seedlings/ } \\
\text { parent }\end{array}$ & $\begin{array}{c}\text { Range } \\
\text { of } \\
r_{\mathrm{TI}}\end{array}$ & $\begin{array}{c}\text { Mean } \\
\mathrm{r}_{\mathrm{TI}}\end{array}$ \\
\hline Brighton & 750 & 6 & 75 & $0.90-0.96$ & 0.93 \\
\hline Carymac & 750 & 3 & 30 & $0.82-0.93$ & 0.87 \\
\hline Cherrygold & 650 & 5 & 52 & $0.89-0.96$ & 0.93 \\
\hline Fireprince & 850 & 8 & 89 & $0.93-0.97$ & 0.95 \\
\hline Flameprince & 850 & 1 & 15 & $0.85-0.91$ & 0.88 \\
\hline Flordacrest & 350 & 5 & 52 & $0.89-0.96$ & 0.92 \\
\hline Flordaking & 450 & 0 & 0 & $0.57-0.60$ & 0.58 \\
\hline Gaschina Nov. & 750 & 6 & 67 & $0.91-0.96$ & 0.94 \\
\hline Goldcrest & 750 & 2 & 30 & $0.83-0.94$ & 0.89 \\
\hline Redskin & 750 & 2 & 20 & $0.78-0.92$ & 0.85 \\
\hline Scarletpearl & 750 & 2 & 20 & $0.60-0.85$ & 0.77 \\
\hline Springold & 850 & 5 & 70 & $0.91-0.96$ & 0.94 \\
\hline Stoneyhard & 850 & 1 & 7 & $0.62-0.85$ & 0.72 \\
\hline Summerprince & 800 & 12 & 117 & $0.93-0.97$ & 0.95 \\
\hline Sunland & 750 & 5 & 70 & $0.90-0.96$ & 0.93 \\
\hline TexRoyal & 650 & 21 & 243 & $0.95-0.97$ & 0.96 \\
\hline Texstar & 550 & 1 & 10 & $0.69-0.88$ & 0.78 \\
\hline Tropic Beauty & 150 & 5 & 53 & $0.91-0.96$ & 0.93 \\
\hline TX3189-1 & 550 & 7 & 82 & $0.91-0.96$ & 0.94 \\
\hline TX3588-2 & 550 & 4 & 50 & $0.87-0.95$ & 0.91 \\
\hline Y11-5 & 550 & 3 & 45 & $0.91-0.95$ & 0.93 \\
\hline
\end{tabular}

${ }^{\mathrm{z}}$ Chilling requirement (CR) measured in chilling units as estimated by the relative blooming time of standard cultivars: EarliGrande (250 CR), Flordaking (450 CR), Texstar (550 CR), JuneGold (650 CR), Harvester (750 CR), and Springold (850 CR). 
of all the traits into one individual. Thus, these data need to be examined from a multitrait perspective.

EARLY RIPENING AND LARGE-FRUITED GENOTYPES. In the medium and low chill stone fruit production regions one of the major objectives is the development of large fruited (fruit weight $>100$ g), early ripening (FDP $<80 \mathrm{~d}$ ) peach cultivars. Unfortunately there is a negative correlated response for fruit weight when selection is for early ripening genotypes (Souza et al., 1998b). This correlated response is $\approx 30 \%$ ( $-4.6 \mathrm{~g}$ ) of the response expected from direct selection for fruit weight $(14.2 \mathrm{~g})$. This correlated response can be somewhat alleviated by also selecting for earlier bloom, which has a positive correlated response for fruit weight (Souza et al., 1998b). This is the approach that peach breeders in regions where an earlier bloom is possible, perhaps inadvertently, have taken. This is reflected in the fact that the early ripening cultivars are the earlier blooming cultivars in areas such as the San Joaquin Valley of California.

Among the genotypes in this study that have a predicted BV less than -10 for FDP, most also have negative BVs for fruit weight. The best parent for this double objective would be 'Goldprince'. It has a high negative BV for FDP $(-11.7)$ and a positive BV for fruit weight (5.2). Other possible parents would be those that either have a near zero BV for fruit weight and high negative BV for FDP ('Springold', 'Cherrygold', 'Summerprince', 'Scarlet Pearl' and 'Texstar') or a high positive BV for fruit weight and a near zero BV for FDP (TX3588-2, BY9-1041, 'Loring', and 'Sunland'). These results reveal that genetic correlations indicate only general tendency (Hill and Leath, 1975).

Table 2. Predicted breeding values (BV), and standard error of the predictions (SEP) of 28 peach genotypes for full bloom date, fruit development period, fruit weight, soluble solids, titratable acidity, fruit blush, fruit shape, fruit density, and blind node propensity. ${ }^{\mathrm{Z}}$

\begin{tabular}{|c|c|c|c|c|c|c|c|c|c|c|c|c|c|c|c|c|c|c|}
\hline \multirow[b]{2}{*}{ Genotype } & \multicolumn{2}{|c|}{$\begin{array}{l}\text { Date } \\
\text { of } \\
\text { full } \\
\text { bloom }\end{array}$} & \multicolumn{2}{|c|}{$\begin{array}{c}\text { Fruit } \\
\text { dev. } \\
\text { period }^{y}\end{array}$} & \multicolumn{2}{|c|}{$\begin{array}{l}\text { Fruit } \\
\text { wt }^{y}\end{array}$} & \multicolumn{2}{|c|}{$\begin{array}{l}\text { Soluble } \\
\text { solids }^{y}\end{array}$} & \multicolumn{2}{|c|}{$\begin{array}{l}\text { Titratable } \\
\text { acidity }^{\mathrm{x}}\end{array}$} & \multicolumn{2}{|c|}{$\begin{array}{l}\text { Fruit } \\
\text { blush }^{\mathrm{x}}\end{array}$} & \multicolumn{2}{|c|}{$\begin{array}{l}\text { Fruit } \\
\text { shape }^{y}\end{array}$} & \multicolumn{2}{|c|}{$\begin{array}{c}\text { Fruit } \\
\text { density }^{y}\end{array}$} & \multicolumn{2}{|c|}{$\begin{array}{c}\text { Blind } \\
\text { node } \\
\text { propensity }\end{array}$} \\
\hline & BV & SEP & BV & SEP & BV & SEP & BV & SEP & BV & SEP & BV & SEP & BV & SEP & BV & SEP & BV & SEP \\
\hline Brighton & 5.1 & 2.1 & -4.2 & 6.7 & -0.3 & 4.3 & -0.85 & 0.53 & -0.34 & 0.34 & 0.64 & 0.57 & $-0.8^{\mathrm{w}} \downarrow$ & 0.2 & 0.39 & 0.15 & 3.7 & 2.9 \\
\hline BY9-1041 & 2.1 & 3.0 & -0.1 & 9.4 & $10.9 \uparrow$ & 6.1 & $1.37 \uparrow$ & 0.75 & 0.33 & 0.48 & 0.51 & 0.81 & $0.5 \uparrow$ & 0.3 & 0.79 & 0.22 & 1.2 & 2.4 \\
\hline Carymac & 3.0 & 3.0 & 4.1 & 9.5 & 1.0 & 6.1 & 0.67 & 0.75 & -0.30 & 0.48 & 0.80 & 0.82 & -0.2 & 0.3 & $-1.21 \downarrow$ & 0.21 & $-5.4 \downarrow$ & 3.9 \\
\hline Cherrygold & -1.4 & 2.3 & $-16.4 \downarrow$ & 7.2 & -2.9 & 4.7 & -0.43 & 0.58 & -0.12 & 0.37 & 1.46 & 0.61 & -0.3 & 0.2 & 0.59 & 0.16 & 1.9 & 3.1 \\
\hline Dixiland & 7.9 & 2.4 & $16.6 \uparrow$ & 7.9 & 3.8 & 5.2 & $3.80 \uparrow$ & 0.63 & $0.94 \uparrow$ & 0.41 & $-3.03 \downarrow$ & 0.68 & -0.5 & 0.2 & -0.19 & 0.18 & -3.8 & 3.3 \\
\hline Earligal & -7.1 & 2.1 & $-19.9 \downarrow$ & 6.8 & $-11.8 \downarrow$ & 4.4 & $-2.17 \downarrow$ & 0.55 & $-0.73 \downarrow$ & 0.35 & 1.91 & 0.58 & -0.4 & 0.2 & $-0.51 \downarrow$ & 0.15 & -2.3 & 0.6 \\
\hline Fireprince & 8.0 & 2.0 & -1.9 & 6.5 & 5.1 & 3.9 & -0.15 & 0.47 & $-0.82 \downarrow$ & 0.30 & 0.78 & 0.54 & -0.5 & 0.2 & 0.17 & 0.14 & 3.9 & 2.5 \\
\hline Flameprince & 7.7 & 3.2 & $11.5 \uparrow$ & 10.6 & $-7.3 \downarrow$ & 3.9 & $1.01 \uparrow$ & 0.47 & 0.32 & 0.30 & $-1.25 \downarrow$ & 0.85 & -0.1 & 0.3 & -0.03 & 0.20 & $11.1 \uparrow$ & 3.5 \\
\hline Flordacrest & $-18.3 \downarrow$ & 2.2 & -5.4 & 7.2 & -5.1 & 4.8 & -0.20 & 0.59 & $0.66 \uparrow$ & 0.39 & $2.52 \uparrow$ & 0.62 & 0.4 & 0.2 & 1.12 & 0.16 & 1.0 & 1.0 \\
\hline Flordaking ${ }^{v}$ & $-12.7 \downarrow$ & 6.6 & -7.2 & 22.0 & -3.4 & 9.7 & -0.44 & 1.15 & $0.54 \uparrow$ & 0.80 & 1.98 & 1.70 & 0.3 & 0.5 & 0.53 & 0.41 & -3.0 & 6.2 \\
\hline \multicolumn{19}{|c|}{ Gaschina } \\
\hline Novembre & $15.1 \uparrow$ & 2.2 & $95.5 \uparrow$ & 7.0 & $-7.0 \downarrow$ & 4.3 & $-0.95 \downarrow$ & 0.53 & 0.37 & 0.34 & $-3.19 \downarrow$ & 0.59 & $-0.8 \downarrow$ & 0.2 & $1.22 \uparrow$ & 0.15 & $10.9 \uparrow$ & 2.8 \\
\hline Goldcrest & 0.5 & 2.7 & $-39.3 \downarrow$ & 8.5 & $-9.9 \downarrow$ & 5.7 & -0.18 & 0.70 & -0.48 & 0.44 & $3.85 \uparrow$ & 0.73 & 0.3 & 0.2 & $1.93 \uparrow$ & 0.20 & $24.4 \uparrow$ & 3.9 \\
\hline Goldprince & -2.5 & 2.0 & -11.7 & 6.5 & 5.2 & 4.0 & $-0.92 \downarrow$ & 0.49 & 0.25 & 0.31 & 1.22 & 0.54 & -0.3 & 0.2 & $-0.60 \downarrow$ & 0.14 & -2.5 & 2.6 \\
\hline Juneprince & 3.7 & 2.0 & -9.8 & 6.4 & 2.7 & 4.0 & -0.82 & 0.5 & -0.02 & 0.32 & 0.57 & 0.54 & -0.4 & 0.2 & -0.06 & 0.28 & -0.04 & 2.4 \\
\hline Loring & $11.1 \uparrow$ & 2.5 & -1.1 & 8.5 & $9.5 \uparrow$ & 5.4 & 0.25 & 0.66 & $-0.90 \downarrow$ & 0.42 & $-1.70 \downarrow$ & 0.72 & $-0.9 \downarrow$ & 0.2 & $-1.70 \downarrow$ & 0.17 & -4.0 & 3.1 \\
\hline Redskin & 7.9 & 3.1 & $17.3 \uparrow$ & 10.0 & $10.1 \uparrow$ & 6.6 & $2.56 \uparrow$ & 0.81 & -0.05 & 0.52 & $-2.20 \downarrow$ & 0.87 & -0.3 & 0.3 & $-1.59 \downarrow$ & 0.22 & 2.5 & 4.2 \\
\hline Scarletpearl & $10.1 \uparrow$ & 4.0 & -12.0 & 13.0 & 0.4 & 7.5 & 0.44 & 0.90 & 0.17 & 0.60 & 2.09 & 1.09 & -0.1 & 0.3 & -0.37 & 0.28 & 2.4 & 4.8 \\
\hline Springold & 2.5 & 2.2 & $-28.7 \downarrow$ & 7.1 & -5.1 & 4.4 & -0.43 & 0.54 & 0.24 & 0.35 & $2.70 \uparrow$ & 0.60 & -0.1 & 0.2 & $1.57 \uparrow$ & 0.16 & $8.3 \uparrow$ & 2.9 \\
\hline Stoneyhard & $15.5 \uparrow$ & 4.2 & $15.6 \uparrow$ & 13.4 & 1.8 & 8.4 & 0.82 & 1.02 & $-3.48 \downarrow$ & 0.67 & $-3.49 \downarrow$ & 1.16 & $-0.8 \downarrow$ & 0.3 & $-0.80 \downarrow$ & 0.30 & $-6.2 \downarrow$ & 5.4 \\
\hline \multicolumn{19}{|l|}{ Summer } \\
\hline prince & 2.5 & 2.0 & -13.1 & 6.3 & -2.2 & 3.9 & -0.37 & 0.47 & -0.20 & 0.30 & $3.02 \uparrow$ & 0.53 & $0.6 \uparrow$ & 0.2 & 0.05 & 0.14 & -4.4 & 2.6 \\
\hline Sunland & $10.0 \uparrow$ & 2.2 & -4.1 & 6.9 & $12.0 \uparrow$ & 4.5 & 0.66 & 0.55 & -0.34 & 0.35 & 1.24 & 0.59 & -0.1 & 0.2 & 1.00 & 0.16 & -3.0 & 3.1 \\
\hline TexRoyal & -3.6 & 1.7 & -6.9 & 5.6 & -2.9 & 3.2 & -0.56 & 0.39 & $0.72 \uparrow$ & 0.25 & 1.64 & 0.46 & 0.3 & 0.1 & -0.42 & 0.12 & $-6.8 \downarrow$ & 2.1 \\
\hline Texstar & -1.0 & 3.8 & -11.7 & 11.9 & -2.6 & 7.7 & $-1.13 \downarrow$ & 0.94 & $-0.69 \downarrow$ & 0.61 & 0.85 & 1.04 & $-0.6 \downarrow$ & 0.3 & 1.06 & 0.27 & -4.8 & 3.8 \\
\hline \multicolumn{19}{|l|}{ Tropic } \\
\hline Beauty & $-34.4 \downarrow$ & 2.3 & 0.6 & 7.3 & -3.0 & 4.6 & -0.36 & 0.57 & $1.40 \uparrow$ & 0.37 & $2.49 \uparrow$ & 0.62 & $1.6 \uparrow$ & 0.2 & $1.39 \uparrow$ & 0.16 & $-9.6 \downarrow$ & 2.9 \\
\hline TX3189-1 - & $-13.4 \downarrow$ & 2.1 & $-17.8 \downarrow$ & 6.7 & $-18.2 \downarrow$ & 4.2 & $-1.27 \downarrow$ & 0.52 & -0.49 & 0.33 & $2.76 \uparrow$ & 0.57 & 0.955 & 0.2 & $1.96 \uparrow$ & 0.14 & -4.1 & 2.8 \\
\hline TX3588-2 & -1.2 & 2.3 & -1.2 & 7.5 & $24.0 \uparrow$ & 5.1 & $1.72 \uparrow$ & 0.63 & 0.28 & 0.40 & -0.29 & 0.65 & $0.6 \uparrow$ & 0.2 & 0.44 & 0.16 & $4.7 \uparrow$ & 3.3 \\
\hline Y11-5 & $-7.1 \downarrow$ & 2.4 & -6.1 & 7.6 & 0.1 & 4.4 & -0.51 & 0.54 & 0.49 & 0.35 & 0.60 & 0.63 & 0.3 & 0.2 & 0.45 & 0.16 & $-9.3 \downarrow$ & 2.9 \\
\hline Y4-55 & 0.5 & 2.2 & $-19.2 \downarrow$ & 7.0 & $-12.2 \downarrow$ & 4.5 & -0.47 & 0.56 & 0.48 & 0.36 & 1.03 & 0.59 & -0.1 & 0.2 & 0.77 & 0.16 & $4.7 \uparrow$ & 3.0 \\
\hline
\end{tabular}

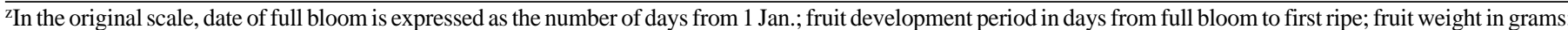

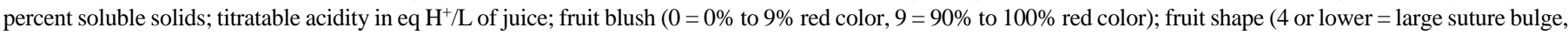

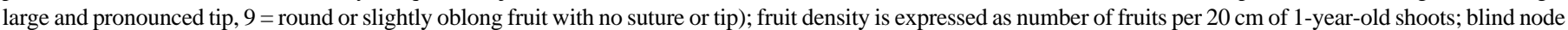
propensity as a percentage of blind nodes.

y Results transformed back to the original scale.

xVariable not transformed.

$\mathrm{w} \downarrow=$ large negative BV and $\uparrow=$ large positive BV.

${ }^{v}$ Used as standard cultivar for determining time of blooming and ripening. 
Therefore, the presence of a high genetic correlation between two traits does not necessarily mean that these traits must increase or decrease together or vice versa.

To be commercially viable, these genotypes, also need to have attractive fruit (high red blush, round shape), fruit with good flavor (SSC >15\%) and moderate titratable acidity (between 6 and $8 \mathrm{meq}$ malic acid/mL juice), and the tree must be productive [fruit density $\approx 1.3$ fruit per $20 \mathrm{~cm}$ and a low propensity $(<40 \%)$ for blind node development].

AtTractiveness. All of the 10 potential parents for developing large fruited, early ripening cultivars have positive or nearzero BVs for blush except for 'Loring'. Of these, six had BVs for blush >1.0 and three >2.0 ('Springold', 'Summerprince', and 'Scarlet Pearl'). Only three had positive BVs for fruit shape ('Summerprince', TX3588-2, and BY9-1041) with the others either near-zero ('Goldprince', 'Springold', 'Cherrygold', 'Scarlet Pearl', and 'Sunland') or highly negative ('Loring' and 'Texstar'). The best parent for these traits is 'Summerprince' that has a high positive BVs for both blush and shape. Other useful materials would be those with a near zero BV for fruit shape and high positive BV for blush ('Goldprince', 'Springold', 'Cherrygold', 'Scarlet Pearl', and 'Sunland') or conversely with a high BV for fruit shape and a near zero BV for blush (TX35882, and BY9-1041). 'Loring' as a parent would produce progeny with poorer than average values for both fruit shape and blush.

Fruit Quality. Good flavor is a concept that is difficult to define and consequently difficult to select. Nevertheless, major factors in determining fruit flavor are SSC and titratable acidity. The goal of the Texas A\&M University stone fruit breeding program is to develop peach cultivars with a SSC $>15 \%$ and a moderate level of titratable acidity (6 to $8 \mathrm{meq}$ malic acid $/ \mathrm{mL}$ juice) (Byrne et al., 1991). This should give an acceptable sugar to acid balance and allow picking of the fruit at a firm stage without excessive acidity. The goal of developing a short FDP and high SSC peach cultivar is difficult due to the negative correlated selection response of SSC to selection for early ripening (Souza et al., 1998b). In fact, among the parents with a high negative BV for FDP (BV less than -10), 'Scarlet Pearl' is the only one with a positive, although small, BV for SSC. In this case, the negative correlated response is equal to the response to direct selection for higher SSC. Thus, the best approach would probably be to use those genotypes that have a high positive BV for SSC and little effect on FDP (TX3588-2 and BY9-1041). Nevertheless, within this germplasm base, it may be impossible or at least very difficult to select simultaneously for short FDP and high SSC. Perhaps the best approach would be to lower the titratable acidity of the short FDP genotypes so the sugar:acid ratio is balanced to allow full expression of the sugars present. This should be relatively easy since selection for early ripening tends to lower the titratable acidity of the population (Souza et al., 1998b).

Productivity. Given that the mean value for fruit density is greater than the required density for a full commercial crop (2.0 vs. 1.3 fruit $/ 20 \mathrm{~cm}$ ) and the mean percentage of blind nodes is lower than the desired minimum level ( $34 \%$ vs. $40 \%$ blind nodes), there is little need to select for fruit density or against blind node propensity (Boonprakob et al., 1994; Byrne, 1986; Souza et al., 1998a; Werner et al., 1988).

Full BLOOM DATE. The date of full bloom is flexible as long as the genotype is productive. In areas where frosts during full bloom are not a production constraint, early blooming can be combined with short FDP to develop earlier ripening genotypes. There are four genotypes that have high negative BV for date of full bloom: 'Tropic Beauty', 'Flordacrest', TX3189-1, and 'Flordaking'. Of these, only TX3189-1 has a highly negative BV for fruit weight whereas the others are near zero. The remaining three all have near-zero to slightly negative BVs for SSC, FDP, and blind node propensity, and positive to highly positive BVs for

Table 3. Selection indices ${ }^{\mathrm{z}}$ for three trait groups and three parental groups for breeding early ripening commercial peach cultivars adapted to medium and low chill regions.

\begin{tabular}{|c|c|c|c|c|}
\hline $\begin{array}{l}\text { Potential } \\
\text { parent }\end{array}$ & $\begin{array}{c}\text { Early and } \\
\text { size }^{\mathrm{y}}\end{array}$ & Attractiveness ${ }^{\mathrm{x}}$ & Quality $^{\mathrm{w}}$ & Composite $^{v}$ \\
\hline & \multicolumn{4}{|c|}{ High negative BV for FDP and positive or near-zero BV for fruit weight } \\
\hline Goldprince & 41.5 & 2.8 & -17.6 & 26.7 \\
\hline Springold & 39.6 & 14.7 & -10.1 & 44.2 \\
\hline Cherrygold & 25.5 & 4.3 & -4.7 & 25.1 \\
\hline Summerprince & 17.1 & 27.1 & -2.6 & 41.6 \\
\hline Scarlet Pearl & 15.1 & 11.0 & 4.1 & 30.2 \\
\hline \multirow[t]{2}{*}{ Texstar } & 16.6 & -3.9 & -6.6 & 6.1 \\
\hline & \multicolumn{4}{|c|}{ Near-zero BV for FDP and high positive BV for fruit weight } \\
\hline TX3588-2 & 75.6 & 7.3 & 21.6 & 104.5 \\
\hline BY9-1041 & 30.8 & 10.6 & 15.6 & 57.0 \\
\hline Loring & 19.6 & -23.7 & 17.3 & 13.2 \\
\hline \multirow[t]{2}{*}{ Sunland } & 34.2 & 5.9 & 15.0 & 55.1 \\
\hline & \multicolumn{4}{|c|}{ High negative BV for bloom time } \\
\hline Tropic Beauty & 26.6 & 38.9 & -26.4 & 39.1 \\
\hline Flordacrest & 13.8 & 21.1 & -12.9 & 22.0 \\
\hline Flordaking & 16.9 & 16.4 & -14.7 & 18.6 \\
\hline TX3189-1 & -5.6 & 30.1 & -26.4 & -1.9 \\
\hline
\end{tabular}

${ }^{\mathrm{z}}$ Selection index $=\sum(\mathrm{BV} \times$ weighing factor $)$.

yEarly and size $=$ weighing factors for FDP $(-7.5 \mathrm{~d})$, fruit weight $(5 \mathrm{~g})$, and bloom time $(-15 \mathrm{~d})$ are $-2.0,3.0$, and -1.0 respectively.

${ }^{\mathrm{x}}$ Attractiveness = weighing factors for blush (2.5 units), and shape (1.0 unit) are 6 and 15 , respectively.

${ }^{\mathrm{w}}$ Quality = weighing factors for soluble solids $(1.0 \%)$, and titratable acidity $\left(-1.0 \mathrm{meq} \cdot \mathrm{mL}^{-1}\right)$ are 15 and -15 , respectively.

${ }^{\mathrm{v}}$ Composite is the sum of the three other columns. 
Table 4. Simple linear correlations ( $r$ ) of predicted breeding values (BV) on parent phenotypic values for nine plant and fruit characteristics of peach.

\begin{tabular}{lccc}
\hline \hline & \multicolumn{3}{c}{ Simple linear correlation $(r)$} \\
\cline { 2 - 4 } Characteristic & 1993 & 1994 & Overall \\
\hline Date of full bloom & $0.86^{* * *}$ & $0.69^{* * *}$ & $0.85^{* * *}$ \\
Fruit development period & $0.82^{* * *}$ & $0.78^{* *}$ & $0.80^{* * *}$ \\
Fruit weight & $0.31^{\mathrm{NS}}$ & $0.29^{\mathrm{NS}}$ & $0.13^{\mathrm{NS}}$ \\
Soluble solids & --- & $0.67^{* *}$ & $0.67^{* *}$ \\
Titratable acidity & --- & $0.44^{\mathrm{NS}}$ & $0.44^{\mathrm{NS}}$ \\
Fruit blush & $0.90^{*}$ & $0.78^{* *}$ & $0.81^{* * *}$ \\
Fruit shape & --- & $0.27^{\mathrm{NS}}$ & $0.27^{\mathrm{NS}}$ \\
Fruit density & $0.20^{\mathrm{NS}}$ & $0.16^{\mathrm{NS}}$ & $0.17^{\mathrm{NS}}$ \\
Blind node propensity & $0.14^{\mathrm{NS}}$ & --- & $0.14^{\mathrm{NS}}$
\end{tabular}

$\mathrm{vs}^{*}, * *, * * * *$ Nonsignificant or significant at $P<0.05,0.01$, or 0.001 , respectively.

blush, shape, titratable acidity, and fruit density. 'Tropic Beauty' would be the best parent for early bloom, high blush, and round shape without adversely affecting the FDP or fruit size but it also transmits higher titratable acidity, which is undesirable especially in the early ripening genotypes, which have lower soluble solids than the later ripening genotypes. 'Flordacrest' and 'Flordaking' would also be useful as they would not increase titratable acidity to the extent that would 'Tropic Beauty' but these parents would be less effective in transmitting desirable fruit shape and early blooming than would 'Tropic Beauty'.

LATE-BLOOMING GENOTYPES FOR THE LOW- AND MEDIUM-CHILL PRODUCTION zONES. In production zones where frosts during bloom are probable, later blooming cultivars generally fruit more consistently (Okie, 1998). There is a general association between date of full bloom and chilling requirement in peaches (Muñoz et al., 1986; Sherman and Rodriguez, 1987; Topp and Sherman, 1989) and consequently relative bloom time is used commonly to estimate the chilling requirement of peach genotypes and their zones of adaptation (Sherman and Rodriguez, 1987). Although many later blooming genotypes fruit poorly under medium chill conditions either due to insufficient chilling to break dormancy or due to higher temperatures during late versus early bloom (Edwards, 1987), there are some peach cultivars that bloom late and still set as heavily as earlier blooming genotypes (Byrne, unpublished data; Zebge and Rumayor, 1995).

Several peach breeding programs are trying to develop late blooming peach genotypes adapted to their medium chill production areas to overcome production constraints of damaging cold weather during bloom (Perez, personal communication; Raseira, personal communication; Van Rooyen, 1988). If bloom time was strongly associated with chilling requirement, this would not be possible. As with many associations, there are exceptions and it does appear possible to select for high fruit density and late bloom. Among the genotypes considered herein, two have both high BV for late bloom (10.0 and $15.1 \mathrm{~d})$ and high fruit density (1.0 and 1.2 fruit/20 cm): 'Sunland' and 'Gaschina Novembre' respectively. The other genotypes that have a BV for late bloom $>7$ d ('Stoneyhard', 'Loring', 'Scarlet Pearl', 'Fireprince', 'Redskin', 'Dixiland', and 'Flameprince'), have either a nearzero or a negative BV for fruit density (Table 2). Although 'Gaschina Novembre' is an excellent parent for the combination of late blooming, late ripening, and high fruit set, it would be a poor parent for fruit quality traits such as good shape, high red blush, large size, or high SSC. 'Sunland' would be a much better parent for most of the quality traits.

The wide range in the predicted BVs for most traits and the failure of any given genotype to be outstanding for all characters, suggests that before choosing the best individuals as parents, the breeder should weigh each trait carefully according to his goals. Theoretically, the most efficient option is the selection index (Falconer, 1989), where the predicted BV for each trait is properly weighted according to their relative economic importance. The index is constructed to improve the aggregate breeding value, which is a particular combination of all the characters to be improved (Falconer, 1989). One difficulty in applying the selection index in peach is the lack of a procedure to effectively weigh the characters of economic importance. An option could be to establish the economic weight considering the proportionality of the characters involved (Baker, 1986). For example, in the case of developing an early ripening peach cultivar, the three most important traits would be FDP, fruit weight, and time of bloom. For these traits, it could be argued that a decrease of $7.5 \mathrm{~d}$ in FDP, a 5-g increase in fruit weight, or a 15-d decrease in bloom time all have the same economic value. Thus, to give them the same value in the index, these traits would be assigned the relative weights of $-2.0,3.0$, and -1.0 respectively. This approach can be used for the traits related to attractiveness (blush and shape) and quality (SSC and titratable acidity). For these traits equivalent economic values would be an increase of 2.5 units of blush (scored from $0=0 \%$ to $10 \%$ and $9=90 \%$ to $100 \%$ blush), 1.0 unit of shape (scored on a 0 to 9 scale), $1 \%$ in SSC, or a decrease of $1 \mathrm{meq}$ malic acid $/ \mathrm{mL}$ in titratable acidity. Hence, the respective weighing factors would be $6,15,15$, and -15 (Table 3 ).

The composite indices for early/size, attractiveness, and quality simplify parental choice and help understand the limitations of this germplasm (Table 3). The early/size index allows direct comparison of the various combinations to obtain this goal and indicates that the better parents would be 'Goldprince', 'Springold', 'Cherrygold', TX3588-2, BY9-1041, 'Sunland', and 'Tropic Beauty'. Within these parents there is a wide range in both attractiveness ('Tropic Beauty' with 38.9 to 'Goldprince' with 2.8) and quality (TX3588-2 with 21.6 and 'Tropic Beauty' with -26.4). The best parents for fruit quality are among those with near zero BV for FDP and high positive BV for fruit weight, while the parents with the poorest quality have either high negative BVs for FDP or high negative BVs for bloom time. In contrast, the parents with the best attractiveness have high negative $\mathrm{BV}$ for bloom time.

There is no parent that has highly desirable BVs for all the traits. Several parents have good selection index values for early/ size and high attractiveness that would indicate that developing commercial cultivars with desirable combinations of these traits should not be difficult. Unfortunately, these parents do not have the desired quality characteristics. Thus, it will be difficult to combine all three groups of traits into one cultivar with the present germplasm. The appropriate approach would be to intercross selected parents from each group with complementary and overall positive indices, followed by selection and intermating of the progeny for two or three generations.

Although BVs are useful to quantify the relative breeding values of specific genotypes and to help analyze breeding difficulties, the use of phenotypic values to select parents among fruit breeding is more common since it is much easier information to collect. In general, if the narrow sense heritability is high, selection based on phenotype is effective (Falconer, 1989; Hansche, 1983). In this study, three traits (date of full bloom, fruit 
development period, and fruit blush) had narrow sense heritabilities $>0.65$. The predicted breeding values of these three traits were well correlated with their parental phenotypic values (Table 4 ), indicating that the less expensive approach of using phenotypic selection would be effective. This reflects the relative ease of manipulating these traits in a breeding population. The other six traits (fruit weight, SSC, titratable acidity, fruit shape, fruit density, blind node propensity) have low narrow sense heritabilities and generally had poor correlations between the predicted breeding values and parental phenotypic values. The only character that had a significant correlation was SSC but unfortunately only 1 year of data were available (Table 4 ). For these traits, the BV would give a better ranking of the genetic value of the parents than would their phenotypic value and, therefore, the selection efficiency would be enhanced and the genetic gain more predictable.

Most low- and mid-chill peach breeding programs in the United States use multiple, but independent selection programs for each trait. In these programs, breeders are usually aware of the difficulties resulting from undesirable genetic correlations among traits. However, little attention has been focused on finding solutions or ways to alleviate these difficulties, and improve the efficiency of their work. The results discussed in this paper indicate that parent's predicted BVs can be used to select the best individuals and to manage problems due to undesirable genetic correlations.

\section{Literature Cited}

Baker, R.J. 1986. Selection index in plant breeding. CRC Press, Boca Raton, Fla.

Boldman, K.G., L.A. Kriese, L.D Van Vleck, C.P. Van Tassel, and S.D. Kachman. 1995. A manual for use of MTDFREML. A set of programs to obtain estimates of variances and covariances. USDA-ARS, Univ. Nebraska, Lincoln, Nebr.

Boonprakob, U., D.H. Byrne, and R.E. Rouse. 1994. A method for blind node evaluation. Fruit Var. J. 48:213-215.

Box, G.E. and D.R. Cox. 1964. An analysis of transformations. J. Royal Stat. Soc. 26:211-243.

Byrne, D.H. 1986. Mechanisms of spring freeze injury avoidance in peach. HortScience 21:1235-1236.

Byrne, D.H., A.N. Nikolic, and E.E. Burns. 1991. Variability in sugars, acids, firmness, and color characteristics of 12 peach genotypes. J. Amer. Soc. Hort. Sci. 116:1004-1006.

Cotterill, P.P. and J.W. James. 1984. Number of offspring and plot sizes required for progeny testing. Silvae Genet. 33:203-209.

Cox, G.M. and K.J. Frey. 1984. Combining ability and the selection of parents for interspecific oat matings. Crop Sci. 24:963-967.

Edwards, G.R. 1987. Temperature in relation to peach culture in the tropics. Acta Hort. 199:61-62.

Falconer, D.S. 1989. Introduction to quantitative genetics. 3rd ed. Longman Sci. and Technol., London.

Gianola, D., J.L. Foulley, and R.L. Fernando. 1986. Prediction of breeding values when variances are not known. Genetique Selection Evolution 18:485-498.

Gordon, G.H. 1980. A method of parental selection and cross prediction using incomplete partial diallels. Theor. Appl. Genet. 56:225-232.

Hansche, P.E. 1983. Response to selection, p. 154-171. In J.N. Moore and J. Janick (eds.). Methods in fruit breeding. Purdue Univ. Press,
West Lafayette, Ind.

Henderson, C.R. 1977. Best linear unbiased estimation and prediction under a selection model . Biometrics 31:423-447.

Henderson, C.R. 1983. Estimation of variances and covariances under multiple trait models. J. Dairy Sci. 67:1581-1589.

Hesse, C.O. 1975. Peaches, p. 285-335. In J. Janick and J.N. Moore (eds.). Methods in fruit breeding. Purdue Univ. Press, West Lafayette, Ind.

Hill, R.R., Jr. and K.T. Leath. 1975. Genotypic and phenotypic correlations for reaction to five foliar pathogens in alfalfa. Theor. Appl. Genet. 45:254-258.

Huber, D.A. 1994. Optimal mating designs and optimal techniques for analysis of quantitative traits in forest genetics. PhD diss. Univ. Fla., Gainesville.

Kennedy, B.W. 1981. Variance component estimation and prediction of breeding values. Can. J. Genet. Cytol. 23:565-578.

Muñoz, C.G., J. Sepulveda, J. García-Huidobro, and W.B. Sherman. 1986. Determining thermal time and base temperature required for fruit development in low-chill peaches. HortScience 21:520-522.

Okie, W.R. 1998. Handbook of peach and nectarine cultivars: Performance in the southeastern United States and index of names. USDA Agr. Hdbk. 714.

Pepper, W.D. and G. Namkoong. 1978. Comparing efficiency of balanced mating designs for progeny testing. Silvae Genet. 27:161-169.

Sherman, W.B. and J. Rodriguez. 1987. Breeding of low-chill peach and nectarine for mild winters. HortScience 22:1233-1236.

Souza, V.A.B., D.H. Byrne, and J.F. Taylor. 1998a. Heritability, genetic and phenotypic correlations, and predicted selection response of several quantitative traits in peach. I. An analysis of several reproductive traits. J. Amer. Soc. Hort. Sci. 123:598-603.

Souza, V.A.B., D.H. Byrne, and J.F. Taylor. 1998b. Heritability, genetic and phenotypic correlations, and predicted selection response of several quantitative traits in peach. II. An analysis of several fruit traits. J. Amer. Soc. Hort. Sci. 123:604-611.

Tancred, S.J. and A.G. Zeppa. 1995. Heritability and patterns of inheritance of the ripening date of apples. HortScience 30:325-328.

Topp, B.L. and W.B. Sherman. 1989. The relationship between temperature and bloom-to-ripening period in low-chill peach. Fruit Var. J. 43:155-158.

Van Rooyen, P.C. 1988. Peach situation in South Africa breeding objectives, p. 220-226. In: N.F. Childers and W.B. Sherman (eds.). The peach. Hort. Press, Gainesville, Fla.

Werner, D.J., B.D. Mowrey, and J.X. Chaparro. 1988. Variability in flower bud number among peach and nectarine cultivars. HortScience 23:578-580.

White, T.L. and G.R. Hodge. 1988. Best linear prediction of breeding values in a forest tree improvement program. Theor. Appl. Genet. 76:719-727.

White, T.L. and G.R. Hodge. 1989. Predicting breeding values with application in forest tree improvement. Kluwer Academic Publ., Dordrecht, The Netherlands.

White, T.L., G.R. Hodge, and M.A. Delorenzo. 1986. Best linear prediction of breeding values in forest tree improvement, p. 99-122. In: Proc. Genet. Breeding Southern Pines. Gainesville, Fla.

Wilcox, C.J. and M.A. Delorenzo. 1983. Progeny testing in dairy cattle, p. 101-113. In: Proc. 1st Intl. Symp. Animal Prod. Ribeirão Preto, São Paulo, Brazil.

Zebge, J.A. and A.F. Rumayor. 1995. Selecciones de duranzo criollo con floración tardía, p. 104-112. In: Reunión Nat. e Internac. Sobre Producción de Duranzo, Chabacano, y Ciruela. Univ. Autónoma de Querétaro, Mexico. 